\title{
Variations of estimated maximal aerobic speed in children soccer players and its associations with the accumulated training load: Comparisons between non, low and high responders
}

Clemente, Filipe Manuel ; Silva, Ana Filipa ; Alves, Ana Ruivo ; Nikolaidis, Pantelis Theodoros ; Ramirez-Campillo, Rodrigo ; Lima, Ricardo ; Söğüt, Mustafa ; Rosemann, Thomas ; Knechtle, Beat

\begin{abstract}
The aim of this study was twofold: (i) to examine the variations of estimated maximal aerobic speed between non, low and high responders and (ii) to analyze the relationships between accumulated training load parameters and variations of maximal aerobic speed in children soccer players. Forty-four male soccer players were assessed three times during the early and mid-season (second to fifth month of the season) and were monitored daily over the period of analysis using the rating of perceived exertion (RPE), recording the training duration (in $\mathrm{min}$ ) and calculating the session-RPE (sRPE). Pairwise comparisons revealed that maximal aerobic speed (MAS) was greater for the third assessment than the first ( $\mathrm{p}$-value $[\mathrm{p}]=0.003$; standardized effect of Cohen $[\mathrm{d}]=0.355)$ and second $(\mathrm{p}=0.013 ; \mathrm{d}=0.193)$ assessments. Large correlations were found between MAS and accumulated RPE, accumulated time, and accumulated sRPE. Moreover, non, low and high responders differed in $\triangle$ MAS $(\mathrm{p}<0.001)$ with the last group presenting the largest improvement in MAS. Results suggest that children with lower MAS baseline levels will improve more this capacity over the early and mid-season period compared to children with better baseline levels. Moreover, associations between accumulated training load and MAS were found, suggesting that the training effort can be related with aerobic capacity changes.
\end{abstract}

DOI: https://doi.org/10.1016/j.physbeh.2020.113030

Posted at the Zurich Open Repository and Archive, University of Zurich

ZORA URL: https://doi.org/10.5167/uzh-188307

Journal Article

Accepted Version

Originally published at:

Clemente, Filipe Manuel; Silva, Ana Filipa; Alves, Ana Ruivo; Nikolaidis, Pantelis Theodoros; Ramirez-Campillo, Rodrigo; Lima, Ricardo; Söğüt, Mustafa; Rosemann, Thomas; Knechtle, Beat (2020). Variations of estimated maximal aerobic speed in children soccer players and its associations with the accumulated training load: Comparisons between non, low and high responders. Physiology and Behavior, 224:113030.

DOI: https://doi.org/10.1016/j.physbeh.2020.113030 


\section{Physiology \& Behavior}

\section{Variations of estimated maximal aerobic speed in children soccer players and its associations with the accumulated training load: comparisons between non, low and high responders}

\begin{tabular}{|c|c|}
\hline Manuscript Number: & PHB_2020_37R1 \\
\hline Article Type: & Research Paper \\
\hline Keywords: & $\begin{array}{l}\text { Association football; internal load.; Aerobic fitness; Performance; children; training } \\
\text { load }\end{array}$ \\
\hline Corresponding Author: & $\begin{array}{l}\text { Filipe Manuel Clemente } \\
\text { Instituto Politécnico de Viana do Castelo, Escola Superior de Desporto e Lazer, } \\
\text { Melgaço, Portugal } \\
\text { Melgaço, PORTUGAL }\end{array}$ \\
\hline First Author: & Filipe Manuel Clemente \\
\hline \multirow[t]{9}{*}{ Order of Authors: } & Filipe Manuel Clemente \\
\hline & Ana Filipa Silva \\
\hline & Ana Alves \\
\hline & Panteleimon Nikolaidis \\
\hline & Rodrigo Ramirez-Campillo \\
\hline & Ricardo Lima \\
\hline & Mustafa Söğüt \\
\hline & Thomas Rosemann \\
\hline & Beat Knechtle \\
\hline Abstract: & $\begin{array}{l}\text { The aim of this study was twofold: (i) to examine the variations of estimated maximal } \\
\text { aerobic speed between non, low and high responders and (ii) to analyze the } \\
\text { relationships between accumulated training load parameters and variations of maximal } \\
\text { aerobic speed in children soccer players. Forty-four male soccer players were } \\
\text { assessed three times during the early and mid-season (second to fifth month of the } \\
\text { season) and were monitored daily over the period of analysis using the rating of } \\
\text { perceived exertion (RPE), recording the training duration (in min) and calculating the } \\
\text { session-RPE (sRPE). Pairwise comparisons revealed that maximal aerobic speed } \\
\text { (MAS) was greater for the third assessment than the first ( } p \text {-value [p] }=0.003 \text {; } \\
\text { standardized effect of Cohen [d] = 0.355) and second ( } p=0.013 ; d=0.193 \text { ) } \\
\text { assessments. Large correlations were found between MAS and accumulated RPE, } \\
\text { accumulated time, and accumulated sRPE. Moreover, non, low and high responders } \\
\text { differed in } \triangle M A S \text { ( } p<0.001 \text { ) with the last group presenting the largest improvement in } \\
\text { MAS. High responders presented positive and moderate correlations between } \triangle M A S \\
\text { and accumulated training load parameters. Results suggest that children with lower } \\
\text { MAS baseline levels will improve more this capacity over the early and mid-season } \\
\text { period compared to children with better baseline levels. Moreover, associations } \\
\text { between accumulated training load and MAS were found, suggesting that the training } \\
\text { effort can be related with higher aerobic capacity. }\end{array}$ \\
\hline \multirow[t]{3}{*}{ Suggested Reviewers: } & $\begin{array}{l}\text { Hugo Sarmento } \\
\text { hg.sarmento@gmail.com } \\
\text { Expert in youth soccer }\end{array}$ \\
\hline & $\begin{array}{l}\text { Daniel Castillo } \\
\text { danicasti5@gmail.com } \\
\text { Expert in youth soccer }\end{array}$ \\
\hline & $\begin{array}{l}\text { Cain Clark } \\
\text { cain.clark@coventry.ac.uk } \\
\text { Expert in youth and exercise }\end{array}$ \\
\hline
\end{tabular}


Eugenia Murawska-Cialowicz

eugenia.murawska-cialowicz@awf.wroc.pl

Expert in exercise physiology

Opposed Reviewers:

Response to Reviewers:

Reviewer \#1:

The paper is interesting and well written and ready for publication, in my opinion. Is seems to be a good piece of science implemented in control of performance in children soccer player

I am sure that the paper will be highly cited for the above reason and will be of great help for those out there interested in scientific coaching.

It possess high practical aspect. I would suggest for the above reason publication. AUTHORS: DEAR REVIEWER, THANK YOU SO MUCH FOR YOUR COMMENTS.

Reviewer \#2:

This is a very well-written article where the authors describe the maximal aerobic speed in children soccer players. The begining of this article has a satisfied structure, strong description and writing skills, explanatory content and quite reasoning according to the results of the individualized groups. The parameters that they have been taken such us age, body mass, height, MAS, $\triangle$ MAS they clarify the same result that younger soccer athletes (positive responders) starting their accumulate program by integrating exercises that improve cardiorespiratory function intensify the type of exercise in terms of intensity, quality, strength until they will become older athletes they have permanent development on contrary with the middle and low athletes responders.

44 male soccer players were assessed 3 times during the early and mid-season (2nd to 5th month of the season) and were monitored daily over the period of analysis using the rating of perceived exertion (RPE), recording the training duration (in min) and calculating the session-RPE (SRPE). Pairwise comparisons revealed that maximal aerobic speed (MAS) was greater for the third assessment than the first $(p-v a l u e[p]=$ 0.003 ; standardized effect of Cohen $[d]=0.355)$ and second $(p=0.013 ; d=0.193)$ assessments.

It is quite clear the boundaries of the selected study cases are completely clarifying as living data examples to demonstrate this specified research, in experimental frame. The reader could almost be immediately aware of the effects of targeted training on certain age limits and how they are carried out. Almost all systems of the body are improved through interaction with each other, which leads to better oxygen supply, better cardiorespiratory function, optimum bone density, stronger muscle nutrition with a common denominator and the positive development of the positive responding athlete. Even though to the references the authors using for the general knowledge frame older bibliography but in the specific era the authors preferring to use the recent sources.

During the reading I felt the absolute logical writing of the essay, which captures the positions, analyzes the parameters with the aim of proving through the context to conclude the staging of the findings results. It has a methematical written row flow. AUTHORS: DEAR REVIEWER, THANK YOU SO MUCH FOR YOUR COMMENTS.

Reviewer \#3:

Introduction

It would have been better to contextualise the physical demands of soccer data around youth soccer. The data does exist see the work of Doncaster et al., 2016. The rationale for the first part of this study is sound. The correlational aspect of this study is limited by the 3 rd variable phenomenon and this needs to be considered later in the manuscript.

AUTHORS: DEAR REVIEWER, THANK YOU SO MUCH. WE HAVE DETAILED IN THE MATCH DEMANDS AND PHYSIOLOGICAL DEMANDAS OCURRED IN YOUNG SOCCER AS WELL AS THE RELATIONSHIP BETWEEN AEROBIC CAPACITY AND PERFORMANCE IN MATCH. 
Methods

Very novice soccer players in terms of training years exposure. It is not clear from the introduction why a pre-adolescent population was selected. There could be a good rationale developed in the Introduction to justify this age group from a physiological stand point. Namely, at this age, the primary energy pathway will be aerobic for these players. This could be developed in the Introduction. Excellent inclusion criteria, but it not clear why the MAS thresholds were determined as they were. Excellent detail on the execution of the MAS test. Shapiro Wilk may have been better.

AUTHORS: DEAR REVIEWER, THANK YOU SO MUCH. WE HAVE WORKED ON THE INTRODUCTION FOLLOWING YOUR RECOMMENDATIONS. THE STATEMENT OF CONTRIBUTION WAS IMPROVED FOLLOWING YOUR SUGGESTIONS.

Results

think that there may be a logic disconnect here. The separation into categories was based upon delta MAS. So, intuitively you would have expected there to be a difference between the groups. The sample sizes of 12,13 and 14 are quite small to really run correlation analyses. You should really have stayed with the pooled data. AUTHORS: DEAR REVIEWER, THANK YOU SO MUCH. WE DO AGREE WITH YOU. FIGURE 4 AND DATA ASSOCIATED WITH THAT WAS REMOVED. ONLY THE POOLED DATA WAS INCLUDED IN THE ANALYSIS.

Discussion:

The development of the aerobic capacity argument is in the Discussion, but some of this needed to be in the Intro. You also need to really focus on the pre-adolescent player, as this is the group that you were working with. The (maturation) aspects are simply not a factor in your study, when the average age is 8 years. This talent identification paradigm does not really fit with the overall theme of this discussion. It is unlikely that at 8 years of age physical precocity will be a determining factor in talent selection in soccer. The concluding statements may be a little strong based upon RPE being the criterion variable for intensity.

AUTHORS: DEAR REVIEWER, THANK YOU SO MUCH. WE HAVE REMOVED THE TOPIC ABOUT TALENT IDENTIFICATION AS WELL AS THE DISCUSSION ABOUT THE MATURATION. MOREOVER, WE HAVE CHANGED THE FINAL REMARKS AND PART OF CONCLUSIONS. 
Filipe Manuel Clemente,

filipe.clemente5@gmail.com

Adress: Complexo Desportivo e Lazer de Melgaço - Monte de Prado, 4960-320,

Melgaço, Portugal

Melgaço, January 11, 2020

Physiology \& Behavior

Dear Editor

\section{Variations of estimated maximal aerobic speed in children soccer players and its associations with the accumulated training load: comparisons between non, low and high responders}

We would like to submit this manuscript as original article for your journal Physiology $\&$ Behavior. This manuscript represents results of original work that have not been published elsewhere. It has not and will not be submitted for publication elsewhere until a decision has been made regarding its acceptability for publication in Physiology \& Behavior. If accepted for publication, it will not be published elsewhere.

The aim of this study was twofold: (i) to examine the variations of estimated maximal aerobic speed between non, low and high responders and (ii) to analyze the relationships between accumulated training load parameters and variations of maximal aerobic speed in children soccer players. Results suggest that children with lower MAS baseline levels will improve more this capacity over the early and mid-season period compared to children with better baseline levels. Moreover, associations between accumulated training load and MAS were found, suggesting that the training effort can be related with higher aerobic capacity.

Yours sincerely, Filipe Manuel Clemente 


\section{Reviewer \#1:}

The paper is interesting and well written and ready for publication, in my opinion. Is seems to be a good piece of science implemented in control of performance in children soccer player I am sure that the paper will be highly cited for the above reason and will be of great help for those out there interested in scientific coaching. It possess high practical aspect. I would suggest for the above reason publication. AUTHORS: DEAR REVIEWER, THANK YOU SO MUCH FOR YOUR COMMENTS.

\section{Reviewer \#2:}

This is a very well-written article where the authors describe the maximal aerobic speed in children soccer players. The begining of this article has a satisfied structure, strong description and writing skills, explanatory content and quite reasoning according to the results of the individualized groups. The parameters that they have been taken such us age, body mass, height, MAS, $\triangle$ MAS they clarify the same result that younger soccer athletes (positive responders) starting their accumulate program by integrating exercises that improve cardiorespiratory function intensify the type of exercise in terms of intensity, quality, strength until they will become older athletes they have permanent development on contrary with the middle and low athletes responders.

44 male soccer players were assessed 3 times during the early and mid-season (2nd to 5th month of the season) and were monitored daily over the period of analysis using the rating of perceived exertion (RPE), recording the training duration (in min) and calculating the session-RPE (sRPE). Pairwise comparisons revealed that maximal aerobic speed (MAS) was greater for the third assessment than the first ( $p$-value $[\mathrm{p}]=0.003$; standardized effect of Cohen $[\mathrm{d}]=0.355$ ) and second ( $p=0.013 ; d=0.193)$ assessments.

It is quite clear the boundaries of the selected study cases are completely clarifying as living data examples to demonstrate this specified research, in experimental frame. The reader could almost be immediately aware of the effects of targeted training on certain age limits and how they are carried out. Almost all systems of the body are improved through interaction with each other, which leads to better oxygen supply, better cardiorespiratory function, optimum bone density, stronger muscle nutrition with a common denominator and the positive development of the positive responding athlete. Even though to the references the authors using for the general knowledge frame older bibliography but in the specific era the authors preferring to use the recent sources.

During the reading I felt the absolute logical writing of the essay, which captures the positions, analyzes the parameters with the aim of proving through the context to conclude the staging of the findings results. It has a methematical written row flow. AUTHORS: DEAR REVIEWER, THANK YOU SO MUCH FOR YOUR COMMENTS. 
Reviewer \#3:

Introduction

It would have been better to contextualise the physical demands of soccer data around youth soccer. The data does exist see the work of Doncaster et al., 2016. The rationale for the first part of this study is sound. The correlational aspect of this study is limited by the 3rd variable phenomenon and this needs to be considered later in the manuscript.

AUTHORS: DEAR REVIEWER, THANK YOU SO MUCH. WE HAVE DETAILED IN THE MATCH DEMANDS AND PHYSIOLOGICAL DEMANDAS OCURRED IN YOUNG SOCCER AS WELL AS THE RELATIONSHIP BETWEEN AEROBIC CAPACITY AND PERFORMANCE IN MATCH.

Methods

Very novice soccer players in terms of training years exposure. It is not clear from the introduction why a pre-adolescent population was selected. There could be a good rationale developed in the Introduction to justify this age group from a physiological stand point. Namely, at this age, the primary energy pathway will be aerobic for these players. This could be developed in the Introduction. Excellent inclusion criteria, but it not clear why the MAS thresholds were determined as they were. Excellent detail on the execution of the MAS test. Shapiro Wilk may have been better.

AUTHORS: DEAR REVIEWER, THANK YOU SO MUCH. WE HAVE WORKED ON THE INTRODUCTION FOLLOWING YOUR RECOMMENDATIONS. THE STATEMENT OF CONTRIBUTION WAS IMPROVED FOLLOWING YOUR SUGGESTIONS.

\section{Results}

think that there may be a logic disconnect here. The separation into categories was based upon delta MAS. So, intuitively you would have expected there to be a difference between the groups. The sample sizes of 12, 13 and 14 are quite small to really run correlation analyses. You should really have stayed with the pooled data. AUTHORS: DEAR REVIEWER, THANK YOU SO MUCH. WE DO AGREE WITH YOU. FIGURE 4 AND DATA ASSOCIATED WITH THAT WAS REMOVED. ONLY THE POOLED DATA WAS INCLUDED IN THE ANALYSIS.

\section{Discussion:}

The development of the aerobic capacity argument is in the Discussion, but some of this needed to be in the Intro. You also need to really focus on the preadolescent player, as this is the group that you were working with. The (maturation) aspects are simply not a factor in your study, when the average age is 8 years. This talent identification paradigm does not really fit with the overall theme of this discussion. It is unlikely that at 8 years of age physical precocity will be a determining factor in talent selection in soccer. The concluding statements may be a little strong based upon RPE being the criterion variable for intensity. AUTHORS: DEAR REVIEWER, THANK YOU SO MUCH. WE HAVE REMOVED THE TOPIC ABOUT TALENT IDENTIFICATION AS WELL AS THE DISCUSSION ABOUT THE MATURATION. MOREOVER, WE HAVE CHANGED THE FINAL REMARKS AND PART OF CONCLUSIONS. 


\section{Highlights}

- Maximal aerobic speed of children soccer players significantly varies across the season

- The baseline levels of maximal aerobic speed determine the patterns of changes across the season

- Training load seems to be correlated with variations in maximal aerobic speed 


\section{Variations of estimated maximal aerobic speed in children soccer players and its associations with the accumulated training load: comparisons between non, low and high responders}

Filipe Manuel Clemente ${ }^{1,2^{*}}$, Ana Filipa Silva ${ }^{1,3,4}$, Ana Ruivo Alves ${ }^{4,5}$, Pantelis Theodoros Nikolaidis ${ }^{6}$, Rodrigo Ramirez-Campillo ${ }^{7}$, Ricardo Lima ${ }^{1,4}$, Mustafa Söğüt ${ }^{8}$, Thomas Rosemann ${ }^{9}$ and Beat Knechtle ${ }^{9,10}$

1 Escola Superior Desporto e Lazer, Instituto Politécnico de Viana do Castelo, Rua Escola Industrial e Comercial de Nun’Álvares, 4900-347, Viana do Castelo, Portugal; filipe.clemente5@ gmail.com; ricardo.lima@esdl.ipvc.pt

2 Instituto de Telecomunicações, Delegação da Covilhã, 6200-001 Covilhã, Portugal

3 N2i, Polytechnic Institute of Maia, 4475-690 Maia, Portugal; anafilsilva@gmail.com

4 The Research Centre in Sports Sciences, Health Sciences and Human Development (CIDESD), Vila Real 5001-801, Portugal

4 Instituto Politécnico de Beja, Departamento de Artes, Humanidades e Desporto, 7800-295 Beja, Portugal

5 Centro de Investigação em Desporto, Saúde e Desenvolvimento Humano (CIDESD), Instituto Universitário da Maia (ISMAI), 4475-690 Maia, Portugal; ana.alves@ipbeja.pt

6 Exercise Physiology Laboratory, 18450 Nikaia, Greece; pademil@ hotmail.com

7 Laboratory of Human Performance. Quality of Life and Wellness Research Group. Department of Physical Activity Sciences. Universidad de Los Lagos. Osorno, Chile. $\underline{\text { r.ramirez@ulagos.cl }}$ 8 Faculty of Sport Sciences, Kırıkkale University, Kırıkkale 71000, Turkey; msogut@kku.edu.tr 9 Institute of Primary Care, University of Zurich, 8091 Zurich, Switzerland; thomas.rosemann@usz.ch

10 Medbase St. Gallen Am Vadianplatz, 9001 St. Gallen, Switzerland; beat.knechtle@ hispeed.ch

Corresponding author: Filipe Manuel Clemente, filipe.clemente5@gmail.com, Adress: Complexo Desportivo e Lazer de Melgaço - Monte de Prado, 4960-320, Melgaço, Portugal 


\title{
Variations of estimated maximal aerobic speed in children soccer players and its associations with the accumulated training load: comparisons between non, low and high responders
}

\begin{abstract}
The aim of this study was twofold: (i) to examine the variations of estimated maximal aerobic speed between non, low and high responders and (ii) to analyze the relationships between accumulated training load parameters and variations of maximal aerobic speed in children soccer players. Forty-four male soccer players were assessed three times during the early and mid-season (second to fifth month of the season) and were monitored daily over the period of analysis using the rating of perceived exertion (RPE), recording the training duration (in min) and calculating the session-RPE (sRPE). Pairwise comparisons revealed that maximal aerobic speed (MAS) was greater for the third assessment than the first ( $p$-value $[\mathrm{p}]=0.003$; standardized effect of Cohen $[\mathrm{d}]=0.355)$ and second $(\mathrm{p}=0.013 ; \mathrm{d}=0.193)$ assessments. Large correlations were found between MAS and accumulated RPE, accumulated time, and accumulated sRPE. Moreover, non, low and high responders differed in $\triangle \mathrm{MAS}(\mathrm{p}<0.001)$ with the last group presenting the largest improvement in MAS. Results suggest that children with lower MAS baseline levels will improve more this capacity over the early and midseason period compared to children with better baseline levels. Moreover, associations between accumulated training load and MAS were found, suggesting that the training effort can be related with aerobic capacity changes.
\end{abstract}

Keywords: children; association football; performance; aerobic fitness; training load; internal load.

\section{Introduction}


Soccer can be characterized as an intermittent sport, with multiple short and very high intense actions interspaced by low-activity demands [1,2]. Therefore, soccer players depend on a well-developed aerobic and anaerobic systems that allow to sustain high-intensity efforts with intermittence during 90 minutes [3,4]. Naturally, aerobic capacity is one of the fundamental fitness components of soccer players allowing covering between 9-12 km in which 1000-1500 meters are performed at high speed running $(>19.8 \mathrm{~km} / \mathrm{h})$ and sprinting (>25 km/h) [5]. In the case of children at the beginning of puberty, maximal oxygen uptake in matches may vary from 50 to $64 \mathrm{~mL} / \mathrm{Kg} / \mathrm{min}$ [6] while physical demands imply $\sim 6500$ meters in which $\sim 670$ is made at high-intensity running and $\sim 300$ at very high intensity running [7]. Also, in children soccer players, it seems that $\mathrm{VO} 2$ kinetics are related to physical measures associated with soccer matches [8], thus justifying the pertinence of a well-prepared aerobic capacity even in children.

Aerobic capacity is one of the topics of great interest to researchers in sports sciences [9]. Among other indicators, maximal oxygen uptake $\left(\mathrm{VO}_{2} \mathrm{max}\right)$ or maximal aerobic speed (MAS) are some of the core variables that may determine the intensity of exercise and make possible to track the aerobic changes of the players across training periods [10]. In the particular case of soccer, the aerobic performance is one of the determinants of physical qualities and can be associated with a better capacity to sustain high effort levels and short recovery during matches [11]. Moreover, good aerobic performance is fundamental for players to withstand long training sessions and matches [12]. Additionally, it has useful effects on several parameters during the match, such as the number of sprints, the number of interactions with the ball, total time spent on high-intensity activities [7] based on the capacity to optimize the recovery during low demanding periods of time [13].

The evidence about aerobic capacity changes in professional soccer players or elite youth players during the season is well-described $[14,15]$. However, the findings in children players are now so well-described. Boraczynski et al. [16] reported decreases in relative $\mathrm{VO}_{2}$ max in 
children after a 2-year training period. In contrast, Alves et al. [17] reported that 8 weeks of intrasession aerobic and strength training increase $\mathrm{VO}_{2} \max$ by around $7.3 \%$ (this value is $3.8 \%$ for children between the ages of 10 and 12 years old). Therefore, monitoring physical readiness parameters in the early ages is a meaningful aspect of the training process because it is an important period of physical development [18]. Consequently, it is necessary to understand and manage all situations and characteristics which can both increase and decrease sports performance to support coaches' short- and long-term decisions [19,20]. Naturally, that fluctuations in aerobic capacity should be also interpreted based on some concurrent factors. In fact, sensitiveness of aerobic changes may be dependent, among others, of the moment of the season, the baseline level of the players or the training load imposed [21].

The association between changes in aerobic capacity and training load promoted by coaches have been reported in professional players [22,23]. Results have been found that there is a positive and meaningful association between the accumulated training load and the improvements in aerobic capacity [24]. The training load can be measured at different levels (internal and external), however, there is a consistent report in the literature about the validity and reliability of perceived exertion scales to quantify the load comparing to objective measures like heart rate or even comparing with GPS-derived measures [25,26]. Despite the importance, the dose-response relationships studied in soccer has not being centered in children players and there is a lack of information about the interaction between the accumulated training load and the changes in cardiorespiratory fitness. In particular, there is a lack of evidence about training intensity occurring in pre-adolescent players, as well as, identification of how these players vary aerobic performance across the season. In fact, children are characterized by a weaker anaerobic capacity and similar aerobic capacity compared to with adults [27]. Thus, and considering the aerobic metabolism as primary pathway, it seems relevant to monitor eventual variations across a season. 
Moreover, commonly $\mathrm{VO}_{2} \max$ is reported as the aerobic capacity indicator in soccer.

However, other key aerobic measures as MAS has been not properly described. This key trait may also be a determinant of soccer performance, namely because determine the threshold velocity of the players before the anaerobic velocity reserve and this may characterize the trainability level of the players and may be a good indicator of performance [28]. Currently, there are few studies that reported the evolution of such parameter in children soccer players [29]. Moreover, considering that baseline levels may influence the aerobic capacity changes across the season, it would be important to know more about the influence of aerobic baseline levels on the capacity to be a non, low or high responder to training and its relation to volume and intensity, like has been studied in elite players [22]. Therefore, the aim of this study was twofold: (i) to examine the variations of estimated MAS between non, low and high responders in the early and mid-season and (ii) to analyze the relationships between accumulated training load parameters and variations of MAS in children soccer players.

\section{Materials and Methods}

\section{Participants}

Forty-four male children soccer players (age: $8.33 \pm 1.18$ years; soccer experience: $1.22 \pm 0.43$ years; body mass: $31.1 \pm 5.9 \mathrm{~kg}$; height: $131.7 \pm 6.5 \mathrm{~cm}$ ) belonging to three different under-10 Portuguese teams participated in this study. The teams were chosen by convenience (proximity between them in terms of geographical distribution) and relationship with the entity responsible to conduct the study. The three teams participated in the same regional competition and presented similar table classifications at the end of data collection $\left(3^{\text {rd }}, 5^{\text {th }}\right.$ and $6^{\text {th }}$ classified with a difference of 5 points between the $3^{\text {rd }}$ and the $6^{\text {th }}$ place). The sample included 6 goalkeepers, 12 defenders, 10 midfielders, 8 fullbacks, and 8 forwards. The 
player's characteristics can be found in Figure 2 and Table 2. Usually, the children have trained 3 times a week (approximately 70 minutes each training) plus one match each weekend (50 minutes per match).

Players were included based on the following criteria: they must have (i) participated in a minimum of $90 \%$ of the training sessions that occurred during the period of analysis; (ii) participated in the three assessments applied during the period of analysis and had their RPE measured after all training sessions; (iii) participated in half of matches occurred in the period of analysis (and at least half of the time of each match); (iv) not been involved in any other competitive or recreational sports; (v) not suffered from an injury longer than 3 days or illness during the period of analysis; and (vi) started the season at the same time as the other participants. The size of the sample was calculated to ensure an alpha of 0.05 and a beta of 0.08 using the GPower software 3.17 (GPower; University of Dusseldorf, Dusseldorf, Germany). The result indicated a sample of 37 which is less than we have included (N=44).

The participants and their parents were informed about the study design as well as the benefits and potential risks of participating. The parents were then invited to sign an informed consent document and both parents and children gave their assent before any of the tests were performed. The participants were free to leave the experiment at any time. The study was approved by a local ethical committee (code number: IPVC-ESDL181002). The study followed the ethical standards of the Declaration of Helsinki for the study in humans.

\section{Experimental approach}

A descriptive case report study using a repeated-measures design to compare the estimated MAS (and its change) of children soccer players across the early and middle of the season (4 months of the season). Players were split by non, low and high responders based on $\triangle$ MAS, considering the following criteria: (i) non responders ( $\mathrm{n}=13, \triangle \mathrm{MAS}$ ranged from -13.46 to $-0.36 \%$ after the season); (ii) low responders ( $n=19, \Delta$ MAS 0.32 to $8.89 \%$ after the 
season); and (iii) high responders ( $\mathrm{n}=12, \Delta \mathrm{MAS} 12.92$ to $37.03 \%$ after the season). Training load parameters were monitored daily in all training sessions (50 training sessions) that occurred between assessments during the study. A correlational study was used to test the relationships between accumulated load and performance in the second and third assessments. The study timeline can be found in Figure 1. The first assessment was performed one month after the beginning of the season (early November), the second assessment occurred in early January ( 2 months after the first assessment), and the third assessment in early March (two months after the second assessment). The training load was monitored in between the assessments. The period 1 of training load occurred between the first and the second assessment. The period 2 of training load monitoring occurred between the second and third assessments. The training load monitoring included the rating of perceived exertion (RPE), training time records, and the session-RPE (sRPE) calculations (detailed information is given in the methods). The three assessments occurred $72 \mathrm{~h}$ after the last match or training session on the same day of the week and at the same time of day. The assessments of anthropometrics occurred in the morning (9.30 a.m.; $23^{\circ} \mathrm{C}$; indoors). The cardiorespiratory fitness tests were conducted in the afternoon $\left(17.30\right.$ p.m.; $16.2 \pm 1.4^{\circ} \mathrm{C}$; outdoors on synthetic turf).

\section{$<$ FIGURE 1 NEAR HERE}

Note: 5-min test correspond to the test to estimate the MAS. The first two measurements with the 5-min test (not included) were performed only as familiarization sessions with the test 


\section{Assessments}

The anthropometric assessments included measurements of height and body mass. A stadiometer (model 213, SECA) was used to measure the height of participants. Two trials were performed by the same observer to ensure the accuracy of the data. The same procedure was performed to measure body mass (BM). A calibrated body scale (model 761, SECA) was used to measure the BM of the participants. Three observers who were previously tested for accuracy collected the data. Body mass index (BMI) was calculated for each participant.

Participants' cardiorespiratory fitness levels were tested using the 5-min test, previously validated for MAS assessment [30]. Players were familiarized with the test at the beginning of the season (two experimental assessments with difference of one week) and instructed to keep the highest speed as possible at a stable level (and avoid fluctuations in the speed of running during the test). During such experimental period (not included in our results) a testretest was conducted to quantify the reliability of the 5-min in the population after 3-min of jogging and 5-min of dynamic stretching. The results of intra-class correlation were very good (ICC $=0.93$ ), confirming the reliability of the test. During the three assessments, the 5min test was preceded by a standardized warm-up consisting of 3-min of jogging and 5-min of dynamic stretching. The test was performed immediately after the warm-up protocol. The test occurred on a synthetic turf field. The track was marked in ten-meter intervals to make it easier to measure the distance covered by each participant. The test was recorded by a digital camera (Go Pro Hero, 2018, $25 \mathrm{~Hz}$, USA) so that the distance covered by each player could be precisely determined. The distance covered by each player (in meters) was divided by 300 seconds (5-min) to estimate the player's MAS [31]. Considering the test has no changes of direction (differently from shuttle run-based tests) no correction equation was added.

\section{Training load monitoring}


The CR-10 Borg's scale (Borg, 1998) was used to monitor the RPE of participants during the period of analysis. The players were familiarized with the scale for one month (starting at the beginning of the season) to improve the accuracy of the scores. A visual analogue scale was also built and introduced to improve the player's perception for the 10-point scale. The scale was presented to each player individually approximately $30 \mathrm{~min}$ after the end of each training session. The same observer presented the scale to all players and collected each player's scores. This observer also collected the time of each training session (in min). The sRPE, calculated by multiplying the CR-10 score by the time of the session (in min) [33], was calculated for each player.

The training load measures (RPE on the CR-10 scale, time of the session, and sRPE) were used to determine the accumulated load over the period of analysis 1 (between the first and the second assessments) and period of analysis 2 (between the second and the third assessments). The accumulated load was the sum of the results of each training load measure recorded during the period of analysis.

\section{Statistical procedures}

The descriptive statistics is presented in form of mean and standard deviation in both figures and tables. The normality and homogeneity of the sample was tested and observed by using Kolmogorov-Smirnov test $(\mathrm{p}>0.05)$ and the Levene's test $(\mathrm{p}>0.05)$, respectively. Considering the preliminary assumptions, a one-way ANOVA with repeated measures was executed to analyze the variations of anthropometrics and cardiorespiratory fitness between the three assessments. The Mauchly's test was used to determine the sphericity of the data. Every time that the sphericity of the data was not observed, and the epsilon was $>0.75$, we have used the Huynh-Feldt correction. In the case of an epsilon $<0.75$, we have used the Greenhouse-Geisser correction. The partial eta squared was also executed to determine the effect size of repeated measures. The pairwise comparisons were tested using the Bonferroni 
post hoc test and the Cohen's $d$ to determine the effect size. Magnitude inferences according to Cohen's d values were made based on the following thresholds: $0.0-0.2$, trivial; $0.2-0.6$, small; 0.6-1.2, moderate; 1.2-2.0, large; >2.0, very large [34]..

The relationships between the cardiorespiratory fitness assessments and the respective accumulated training load in the periods 1 and 2 were tested using the Pearson $\mathrm{r}$. The magnitudes of the correlation coefficients (r) were interpreted based on the following thresholds [34]: 0.0-0.1, trivial; 0.1-0.3, small; $0.3-0.5$, moderate; $0.5-0.7$, large; $0.7-0.9$, very large; $0.9-1.0$, nearly perfect. Confidence intervals of $95 \%$ were used for the correlation values (r). In addition, the percentage change in MAS ( $\triangle \mathrm{MAS}$ ) from the first (MAS_1), second (MAS_2) to the third (MAS_3) measurement was calculated using the formula '100×(MAS_3-MAS_1)/MAS_1'. Then, the participants were classified to three groups, non responders $(\mathrm{n}=13, \Delta$ MAS ranged from -13.46 to $-0.36 \%)$, low responders $(\mathrm{n}=19,0.32$ $8.89 \%)$ and high responders $(\mathrm{n}=12,12.92-37.03 \%)$, based on $\Delta$ MAS. The statistical procedures were executed on SPSS software (version 24.0, IBM, USA). Significance was set at $\mathrm{p}<0.05$.

\section{Results}

The accumulated training load of the two observational periods (period 1: between $1^{\text {st }}$ and the $2^{\text {nd }}$ assessments; period 2: between the $2^{\text {nd }}$ and the $3^{\text {rd }}$ assessments; see in detail in the Figure 1) can be observed in Table 1. 
Descriptive statistics of MAS performance across the three assessments conducted over the season can be observed in Figure 2. Repeated measures ANOVA revealed significant differences in the 5-min test $(\mathrm{p}=0.001$; partial eta squared $=0.174)$ and the respective MAS ( $p=0.001$; partial eta squared $=0.174)$ during the three assessments conducted over the season. Pairwise comparisons revealed that the performance in the 5-min test was better in the third assessment in comparison with the first (dif: 49.80; $p=0.003 ; d=0.370$, small effect) and the second (dif: $24.75 ; \mathrm{p}=0.013 ; \mathrm{d}=0.200$, small effect) assessments. Moreover, it was also found that MAS was greater in the third than in the first (dif: $0.17 ; \mathrm{p}=0.003 ; \mathrm{d}=$ 0.355, small effect) and second (dif: 0.08; $\mathrm{p}=0.013 ; \mathrm{d}=0.193$, trivial effect) assessments.

\section{$<$ FIGURE 2 NEAR HERE}

The accumulated training load parameters during the two observed periods were associated with the maximal aerobic speed of the second and third assessments. The correlation coefficients can be found in the Figure 3. Large correlations were found between MAS and the accumulated RPE $(r=0.62,[0.44 ; 0.75] ; p=0.000)$, accumulated time $(r=0.63$, $[0.45 ; 0.76] ; \mathrm{p}=0.000)$ and accumulated $\operatorname{sRPE}(\mathrm{r}=0.65,[0.48 ; 0.78]) ; \mathrm{p}=0.000)$ in the observed period 1 (first two months of training). Similarly, in the observed period 2 (second two months of training) large correlations were found between MAS and the accumulated RPE $(r=0.58,[0.39 ; 0.73] ; p=0.000)$, accumulated time $(r=0.62,[0.43 ; 0.75] ; p=0.000)$ and accumulated $\operatorname{sRPE}(\mathrm{r}=0.63,[0.46 ; 0.76]) ; \mathrm{p}=0.000)$. 
Non responders, low responders and high responders differed in $\triangle$ MAS $(p<0.001)$ with the high responders presenting the largest improvement in MAS (Table 2). They differed in MAS_1, where non responders had higher MAS $(+0.60 \mathrm{~m} / \mathrm{s})$ than the high responders $(\mathrm{p}=$ $0.000 ; \mathrm{d}=1.858$, large effect). No difference in any other variable was observed among these groups ( $\mathrm{p}>0.05)$. The $\triangle \mathrm{MAS}$ was significantly greater in high responders comparing to non $(p=0.000 ; d=4.568$, very large effect $)$ and low responders $(p=0.000 ; d=3.620$, very large effect).

$<$ TABLE 2 NEAR HERE

\section{Discussion}

In the present study, variations in MAS were analyzed over a season. A greater MAS was found in the third assessment (4-months after the baseline test) than in the first (baseline) and second assessments (2-months after the baseline). Regarding the different groups, high responders presented the greatest improvements $(\sim 21 \%)$, in opposition to the low responders that showed a decrease in MAS capacity ( 4\%). Additionally, this study aimed to analyze the relationships between accumulated training load parameters and cardiorespiratory performance. In this regard, large correlations were found between MAS and accumulated RPE, accumulated time, and accumulated sRPE. 
The aerobic energy system is essential for coping with long training sessions and soccer matches $[16,35]$. A healthy aerobic energy system is a distinguishable feature among adult elite players [36]. Nevertheless, even in elite soccer players below 15 and 16 years of age, the aerobic component of fitness was shown to be the most important fitness capacity [37]. Similar results were observed in an younger group (age $14.5 \pm 0.4$ years) during 8 months of soccer training [38]. However, it should be noted that increases in anthropometric traits, body mass, skeletal muscle mass, heart and lung mass, hemoglobin levels, blood volume, and nervous system maturation may lead to changes in aerobic capacity $[10,39]$. On the other hand, the low amount of androgen available in a child's body does not contribute as much to cardiac muscle hypertrophy, hemoglobin stimulation, or metabolic enzyme synthesis [40], resulting in low trainability of children between 4 to 12 years of age [41,42]. In fact, it was previously found that relative maximal aerobic capacity and the absolute aerobic power begin to increase several years before the growth spurt and continues to increase after that milestone $[39,43]$. This suggests that the earlier the development of cardiorespiratory capability is stimulated (according to the player's age), the greater their progression. Thus, early cardiorespiratory development is likely to benefit all players: as they get older, they will need to have high levels of aerobic fitness to cope with the intense weekly training sessions regardless of what playing position they specialize [44].

In the present study, only non responders did not show an improvement in MAS values, presenting a decrease of almost $4 \%$. In opposition, in the high responders group it was observed an increase of almost $21 \%$, and an improvement of almost $4 \%$ in low responders from the first to the third moment of evaluation (four months between first and third assessments). Differences among groups may be related to genetic $[45,46]$. In fact, it is usual to present the mean values of the entire sample, remaining unclear whether missing endurance changes or smaller values of improvement in some participants and some variables are caused by training regimen or they are inherent to the participant [45]. 
The use of RPE to monitor training load has been widely validated and used in adults in different sports $[26,47]$. RPE is considered a simple, useful, valid, and inexpensive method for monitoring training load [48]. However, some concerns have emerged among researchers who have observed child soccer players. For example, children may find it difficult to use the RPE measurement scale because of their low level of cognitive development [49]. Nevertheless, studies have shown that children athletes are able to use this scale correctly [50-53]. The present study seems to confirm that capability, since all the parameters used to analyze internal load showed a positive and large correlation with MAS (with the entire sample), indicating that, in general, players were aware of the training effort. However, this relationship seems to be more strengthened when analyzing the high responders group, as they presented a large correlation between MAS and accumulated RPE, accumulated time, and accumulated sRPE, in opposition to the other two groups that presented a small inverse correlation.

One possible limitation of this study is related to the lack of differentiation of field positions. Such differences were noted in previous studies among goalkeepers and other players at a young age [44]. Nonetheless, these studies did not show any such differences in older players (U13 to U15) [56,58]. In this regard, Deprez et al. [35] suggest that the different demands of the field positions assumed at the senior level are not fully developed in soccer players between the ages of 8 and 14 years. Deprez et al. [35] also examined that playing position at those ages could change. Therefore, as suggested previously, development programs in children soccer should be based on changes in parameters over time [59]. Finally, the chose for the 5-min test can be also considered a limitation considering the fact that is a field-based test and no specific for intermittent sports (without changes of direction as shuttle run-based tests). However, the use of continuous running decreases the influence of muscular strength and neuromuscular reactivity [30] and this was the basis for not use a shuttle runbased test. 
As a novelty, this study revealed that progressive increases in MAS occurred in high responders across the season, in opposition to low responders, that lowered its values. Those results were largely correlated with perceived effort and training load reported during the sessions. Such fact is relatively new in children of this age and should be emphasized aiming to determine that, possibly, the intensity of the session may partially explain the improvements in the MAS. However, such fact should be carefully analyzed in future studies since RPE is merely one of many different variables that represent the intensity of a session.

\section{Conclusions}

The main findings of this study are that MAS was significantly improved during the season and that the performance of children players in cardiorespiratory field-based tests was largely correlated with the accumulated training load parameters. Professionals (e.g. fitness trainers, coaches) working with children soccer players should consider analyzing the season aerobic performance and identify the strategies to avoid declines in performance.

Funding: This research received no external funding.

Conflicts of Interest: The authors declare no conflict of interest.

\section{References}

[1] P.S. Bradley, A. Dellal, M. Mohr, J. Castellano, A. Wilkie, Gender differences in match performance characteristics of soccer players competing in the UEFA 
Champions League, Hum. Mov. Sci. 33 (2014) 159-171. doi:10.1016/j.humov.2013.07.024.

[2] S. Gil, F. Ruiz, A. Irazusta, J. Gil, J. Irazusta, Selection of young soccer players in terms of anthropometric and physiological factors, J. Sports Med. Phys. Fitness. 47 (2007) 25-32.

[3] J. Helgerud, L.C. Engen, U. Wisløff, J. Hoff, Aerobic endurance training improves soccer performance, Med. Sci. Sport. Exerc. 33 (2001) 1925-1931.

[4] T. Stølen, K. Chamari, C. Castagna, U. Wisløff, Physiology of soccer: An update, Sport. Med. (2005). doi:10.2165/00007256-200535060-00004.

[5] M. Mohr, P. Krustrup, J. Bangsbo, Match performance of high-standard soccer players with special reference to development of fatigue, J. Sports Sci. 21 (2003) 519-528. doi:10.1080/0264041031000071182.

[6] J. Stroyer, L. Hansen, K.L.A.U.S. Klausen, Physiological profile and activity pattern of young soccer players during match play, Med. Sci. Sports Exerc. 36 (2004) 168174.

[7] M. Buchheit, A. Mendez-Villanueva, B.M. Simpson, P.C. Bourdon, Match Running Performance and Fitness in Youth Soccer, Int. J. Sports Med. 31 (2010) 818-825. doi:10.1055/s-0030-1262838.

[8] G. Doncaster, S. Marwood, J. Iga, V. Unnithan, Influence of oxygen uptake kinetics on physical performance in youth soccer, Eur. J. Appl. Physiol. 116 (2016) 1781- 
[9] H.M. Carvalho, M.J. Coelho-e-Silva, J.C. Eisenmann, R.M. Malina, Aerobic Fitness, Maturation, and Training Experience in Youth Basketball, Int. J. Sports Physiol. Perform. 8 (2013) 428-434. doi:10.1123/ijspp.8.4.428.

[10] M. Boraczyński, T. Boraczyński, R. Podstawski, Z. Wójcik, Relationships between anthropometric traits, body composition and aerobic capacity in male soccer players aged 13-15 years, J Kinesiol. Exer Sci. 69 (2015) 33-40.

[11] J. Bangsbo, F.M. Iaia, P. Krustrup, The Yo-Yo Intermittent Recovery Test, Sport. Med. 38 (2008) 37-51. doi:10.2165/00007256-200838010-00004.

[12] D. Deprez, J. Fransen, M. Lenoir, R.M. Philippaerts, R. Vaeyens, A retrospective study on anthropometrical, physical fitness, and motor coordination characteristics that influence dropout, contract status, and first-team playing time in high-level soccer players aged eight to eighteen years, J. Strength Cond. Res. 29 (2015) 16921704.

[13] M. Svensson, B. Drust, Testing soccer players., J. Sports Sci. 23 (2005) 601-18. doi:10.1080/02640410400021294.

[14] M.A. Michaelides, K.M. Parpa, A.I. Zacharia, Effects of an 8-Week Pre-seasonal Training on the Aerobic Fitness of Professional Soccer Players, J. Strength Cond. Res. (2019) 1. doi:10.1519/JSC.0000000000003209.

[15] V. Manou, A.A. Dalamitros, S. Kellis, Variations in important aerobic fitness 
parameters and physical characteristics during two consecutive preseason periods in adolescent soccer players, Hum. Mov. 2018 (2018) 75-81. doi: $10.5114 / \mathrm{hm} .2018 .74062$.

[16] M. Boraczyński, T. Boraczyński, R. Podstawski, Z. Wójcik, Relationships between anthropometrics traits, body composition and aerobic capacity in male soccer players aged 13-15 years, J. Kinesiol. Exerc. Sci. 69 (2015) 33-40. doi:10.5604/17310652.1192078.

[17] A.R. Alves, C.C. Marta, H.P. Neiva, M. Izquierdo, M.C. Marques, Does Intrasession Concurrent Strength and Aerobic Training Order Influence Training-Induced Explosive Strength and VO2max in Prepubescent Children?, J. Strength Cond. Res. 30 (2016) 3267-3277. doi:10.1519/JSC.0000000000001431.

[18] M. Dragijsky, T. Maly, F. Zahalka, E. Kunzmann, M. Hank, Seasonal Variation of Agility, Speed and Endurance Performance in Young Elite Soccer Players, Sports. 5 (2017) 12. doi:10.3390/sports5010012.

[19] A.R. Barker, N. Armstrong, Exercise Testing Elite Young Athletes, in: Elit. Young Athl., KARGER, Basel, 2010: pp. 106-125. doi:10.1159/000320642.

[20] A. Hevilla-Merino, A. Castillo Rodríguez, Fluctuation of the Psychological Characteristics of Sports Performance on Young Soccer Players. Basal State vs. Precompetitive, Cuad. Psicol. Del Deport. 18 (2018) 169-178.

[21] V.I. Kalapotharakos, G. Ziogas, S.P. Tokmakidis, Seasonal aerobic performance 
variations in elite soccer players, J. Strength Cond. Res. 25 (2011) 1502-1507. doi:10.1519/JSC.0b013e3181da85a9.

[22] F.M. Clemente, P.T. Nikolaidis, T. Rosemann, B. Knechtle, Dose-Response Relationship Between External Load Variables, Body Composition, and Fitness Variables in Professional Soccer Players, Front. Physiol. 10 (2019). doi:10.3389/fphys.2019.00443.

[23] J.F. Fitzpatrick, K.M. Hicks, P.R. Hayes, Dose-Response Relationship between Training Load and Changes in Aerobic Fitness in Professional Youth Soccer Players, Int. J. Sports Physiol. Perform. ahead-of-p (2018) 1-22. doi:10.1123/ijspp.20170843.

[24] M.A. Campos-Vazquez, F.J. Toscano-Bendala, J.C. Mora-Ferrera, L.J. SuarezArrones, Relationship Between Internal Load Indicators and Changes on Intermittent Performance After the Preseason in Professional Soccer Players, J. Strength Cond. Res. 31 (2017) 1477-1485. doi:10.1519/JSC.0000000000001613.

[25] D. Casamichana, J. Castellano, J. Calleja-Gonzalez, J. San Román, C. Castagna, Relationship Between Indicators of Training Load in Soccer Players, J. Strength Cond. Res. 27 (2013) 369-374. doi:10.1519/JSC.0b013e3182548af1.

[26] M. Haddad, G. Stylianides, L. Djaoui, A. Dellal, K. Chamari, Session-RPE Method for Training Load Monitoring: Validity, Ecological Usefulness, and Influencing Factors, Front. Neurosci. 11 (2017). doi:10.3389/fnins.2017.00612. 
[27] E. Leclair, B. Borel, D. Thevenet, G. Baquet, P. Mucci, S. Berthoin, Assessment of Child-Specific Aerobic Fitness and Anaerobic Capacity by the Use of the PowerTime Relationships Constants, Pediatr. Exerc. Sci. 22 (2010) 454-466. doi:10.1123/pes.22.3.454.

[28] D. Baker, N. Heaney., Normative data for maximal aerobic speed for field sport athletes: A brief review, J. Aust. Strength Cond. 23 (2015) 60-67.

[29] A. Mendez-Villanueva, M. Buchheit, S. Kuitunen, T.K. Poon, B. Simpson, E. Peltola, Is the Relationship Between Sprinting and Maximal Aerobic Speeds in Young Soccer Players Affected by Maturation?, Pediatr. Exerc. Sci. 22 (2010) $497-$ 510. doi:10.1123/pes.22.4.497.

[30] P. Berthon, N. Fellmann, M. Bedu, B. Beaune, M. Dabonneville, J. Coudert, A. Chamoux, A 5-min running field test as a measurement of maximal aerobic velocity, Eur. J. Appl. Physiol. 75 (1997) 233-238. doi:10.1007/s004210050153.

[31] D. Baker, Recent trends in highintensity aerobic training for field sports, Prof Strength Cond. 22 (2011) 3-8.

[32] G. Borg, Perceived exertion and pain scales, Human Kinetics, Champaign IL, USA, 1998.

[33] C. Foster, J.A. Florhaug, J. Franklin, L. Gottschall, L.A. Hrovatin, S. Parker, P. Doleshal, C. Dodge, A new approach to monitoring exercise training, J. Strength Cond. Res. 15 (2001) 109-115. 
[34] W.G. Hopkins, S.W. Marshall, A.M. Batterham, J. Hanin, Progressive Statistics for Studies in Sports Medicine and Exercise Science, Med. Sci. Sport. Exerc. 41 (2009) 3-13. doi:10.1249/MSS.0b013e31818cb278.

[35] D. Deprez, J. Fransen, J. Boone, M. Lenoir, R. Philippaerts, R. Vaeyens, Characteristics of high-level youth soccer players: variation by playing position, J. Sports Sci. 33 (2015) 243-254. doi:10.1080/02640414.2014.934707.

[36] T. Reilly, A.M. Williams, A. Nevill, A. Franks, A multidisciplinary approach to talent identification in soccer, J. Sports Sci. 18 (2000) 695-702.

[37] R. Vaeyens, R.M. Malina, M. Janssens, B. Van Renterghem, J. Bourgois, J. Vrijens, R.M. Philippaerts, A multidisciplinary selection model for youth soccer: the Ghent Youth Soccer Project, Br. J. Sports Med. 40 (2006) 928-934.

[38] M.A. Hammami, A. Ben Abderrahmane, A. Nebigh, E. Le Moal, O. Ben Ounis, Z. Tabka, H. Zouhal, Effects of a soccer season on anthropometric characteristics and physical fitness in elite young soccer players, J. Sports Sci. 31 (2013) 589-596.

[39] T. Stølen, K. Chamari, C. Castagna, U. Wisløff, Physiology of Soccer, Sport. Med. 35 (2005) 501-536.

[40] T. Reilly, J. Bangsbo, A. Franks, Anthropometric and physiological predispositions for elite soccer., J. Sports Sci. 18 (2000) 669-83. doi:10.1080/02640410050120050.

[41] B. Ekblom, Effect of physical training in adolescent boys., J. Appl. Physiol. 27 (1969) 350-355. 
[42] T. Reilly, J. Bangsbo, A. Franks, Anthropometric and physiological predispositions for elite soccer, J. Sports Sci. 18 (2000) 669-683.

[43] R.M. Malina, C. Bouchard, O. Bar-Or, Growth, maturation, and physical activity, Human kinetics, 2004.

[44] D. Deprez, J. Fransen, J. Boone, M. Lenoir, R. Philippaerts, R. Vaeyens, Characteristics of high-level youth soccer players: variation by playing position, J. Sports Sci. 33 (2015) 243-254.

[45] T.N. Mann, R.P. Lamberts, M.I. Lambert, High Responders and Low Responders: Factors Associated with Individual Variation in Response to Standardized Training, Sport. Med. 44 (2014) 1113-1124. doi:10.1007/s40279-014-0197-3.

[46] F. Scharhag-Rosenberger, S. Walitzek, W. Kindermann, T. Meyer, Differences in adaptations to 1 year of aerobic endurance training: individual patterns of nonresponse, Scand. J. Med. Sci. Sports. 22 (2012) 113-118. doi:10.1111/j.16000838.2010.01139.x.

[47] F.M. Clemente, A. Rabbani, J.P. Araújo, Ratings of perceived recovery and exertion in elite youth soccer players: Interchangeability of 10-point and 100-point scales, Physiol. Behav. 210 (2019) 112641. doi:10.1016/j.physbeh.2019.112641.

[48] M.S. Aoki, A.F. Arruda, C.G. Freitas, B. Miloski, P.R. Marcelino, G. Drago, M. Drago, A. Moreira, Monitoring training loads, mood states, and jump performance over two periodized training mesocycles in elite young volleyball players, Int. J. 
Sports Sci. Coach. 12 (2017) 130-137. doi:10.1177/1747954116684394.

[49] G. Borg, Borg's perceived exertion and pain scales., Human kinetics, 1998.

[50] B. Marinov, S. Mandadjieva, S. Kostianev, Pictorial and verbal category- ratio scales for effort estimation in children, Child. Care. Health Dev. 34 (2008) 35-43.

[51] J.N. Roemmich, J.E. Barkley, L.H. Epstein, C.L. Lobarinas, T.M. White, J.H. Foster, Validity of PCERT and OMNI walk/run ratings of perceived exertion., Med. Sci. Sports Exerc. 38 (2006) 1014-1019.

[52] R.G. Eston, D.M. Lambrick, A. V Rowlands, The perceptual response to exercise of progressively increasing intensity in children aged 7-8 years: validation of a pictorial curvilinear ratings of perceived exertion scale, Psychophysiology. 46 (2009) 843851.

[53] J.M. Erichsen, B.J. Dykstra, M.C. Hidde, A.D. Mahon, Ratings of Perceived Exertion and Physiological Responses in Children During Exercise, Int. J. Sports Med. 38 (2017) 897-901.

[54] S.M. Gil, A. Badiola, I. Bidaurrazaga-Letona, J. Zabala-Lili, L. Gravina, J. SantosConcejero, J.A. Lekue, C. Granados, Relationship between the relative age effect and anthropometry, maturity and performance in young soccer players, J. Sports Sci. 32 (2014) 479-486.

[55] N. Hirose, Relationships among birth-month distribution, skeletal age and anthropometric characteristics in adolescent elite soccer players, J. Sports Sci. 27 
(2009) 1159-1166.

[56] P.-L. Wong, K. Chamari, A. Dellal, U. Wisløff, Relationship between anthropometric and physiological characteristics in youth soccer players., J. Strength Cond. Res. 23 (2009) 1204-10. doi:10.1519/JSC.0b013e31819f1e52.

[57] R. Vaeyens, M. Lenoir, A.M. Williams, R.M. Philippaerts, Talent identification and development programmes in sport, Sport. Med. 38 (2008) 703-714.

[58] R.M. Malina, J.C. Eisenmann, S.P. Cumming, B. Ribeiro, J. Aroso, Maturityassociated variation in the growth and functional capacities of youth football (soccer) players 13-15 years., Eur. J. Appl. Physiol. 91 (2004) 555-62. doi:10.1007/s00421003-0995-z.

[59] M.J.C. e Silva, A.J. Figueiredo, F. Simoes, A. Seabra, A. Natal, R. Vaeyens, R. Philippaerts, S.P. Cumming, R.M. Malina, Discrimination of U-14 soccer players by level and position, Int. J. Sports Med. 31 (2010) 790-796.

\section{TABLES}

Table 1. Descriptive statistics (mean and standard deviation) of accumulated training load in the two observed periods (period 1 - trainings between the first and the second assessments and period 2 - trainings between the second and the third assessments).

\begin{tabular}{ccc}
\hline & Period 1 & Period 2 \\
\hline Training sessions (N) & $21.3(6.8)$ & $30.3(5.5)$ \\
Accumulated RPE (A.U.) & $125.88(78.84)$ & $165.44(78.22)$
\end{tabular}



Accumulated time (min)
$1351.77(811.19)$
$1810.52(854.97)$
Accumulated sRPE (A.U.)
$9937.19(7976.44)$
$12877.19(8142.79)$

RPE: rating of perceived exertion in the CR-10 Borg's scale; sRPE: session-RPE using the Foster's method

Table 2. Comparison among responders and non responders.

\begin{tabular}{cccc}
\hline Variable & Non responders $(\mathrm{n}=13)$ & Low responders $(\mathrm{n}=19)$ & High responders $(\mathrm{n}=12)$ \\
\hline Age_1 (years) & $8.62 \pm 1.19$ & $8.63 \pm 1.30$ & $7.92 \pm 0.90$ \\
Body mass_1 $(\mathrm{kg})$ & $34.1 \pm 4.6$ & $31.5 \pm 5.6$ & $28.9 \pm 6.2$ \\
Height_1 (cm) & $134.1 \pm 6.6$ & $132.5 \pm 4.9$ & $129.4 \pm 7.8$ \\
MAS_1 (m/s) & $3.46 \pm 0.42$ & $3.14 \pm 0.53$ & $2.86 \pm 0.16^{\mathrm{a}}$ \\
MAS_2 (m/s) & $3.32 \pm 0.36$ & $3.21 \pm 0.54$ & $3.21 \pm 0.18$ \\
MAS_3 (m/s) & $3.32 \pm 0.38$ & $3.25 \pm 0.53$ & $3.45 \pm 0.17$ \\
$\Delta$ MAS $(\%)$ & $-4.15 \pm 3.60$ & $3.75 \pm 2.52$ & $20.87 \pm 6.97^{\mathrm{a}, \mathrm{b}}$
\end{tabular}

MAS=maximal aerobic speed; $\triangle \mathrm{MAS}=$ change from MAS_1 to MAS_3.; ${ }^{\mathrm{a}}$ : significantly $(\mathrm{p}<0.05)$ different from non responders; ${ }^{\mathrm{b}}$ : significantly $(\mathrm{p}<0.05)$ different from low responders.

\section{FIGURES}




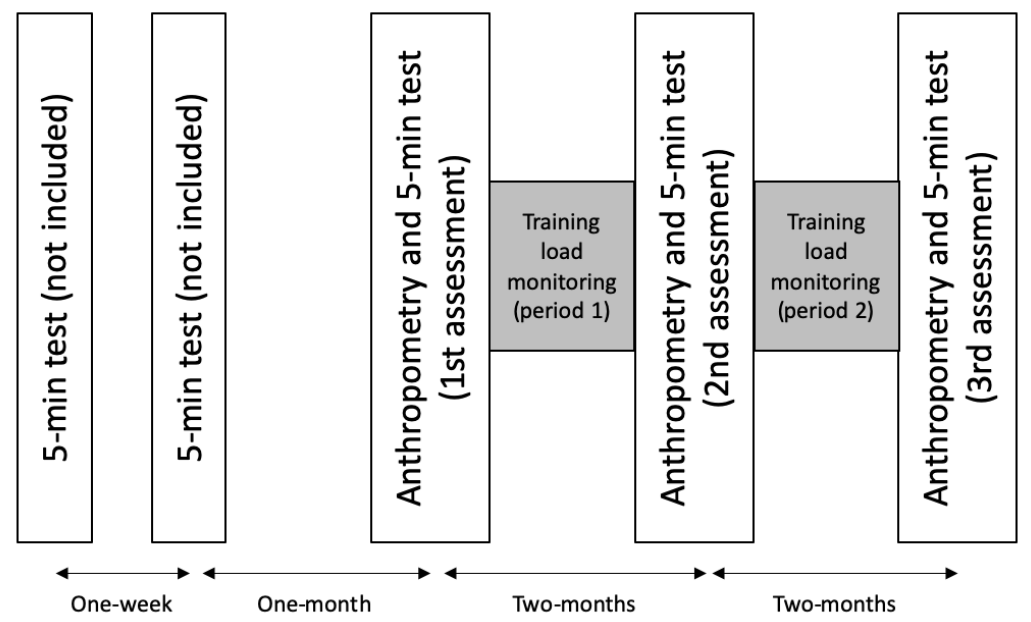

Figure 1. Study timeline.

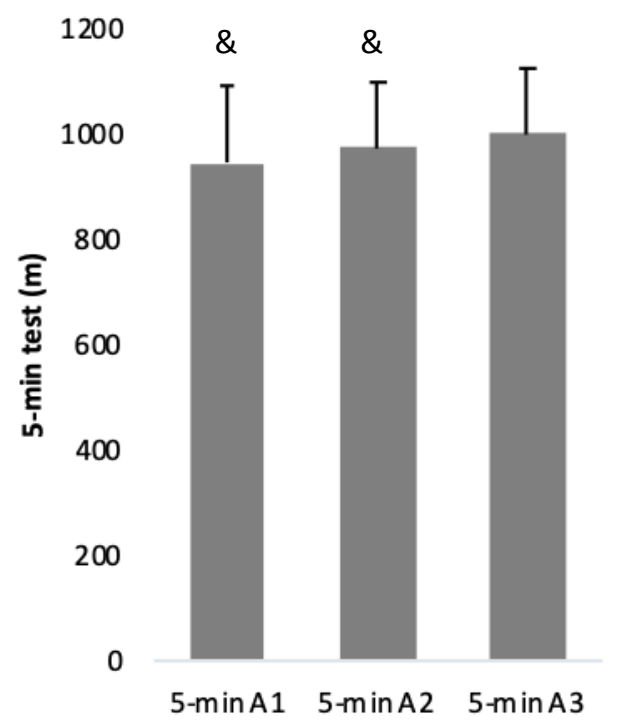

(a)

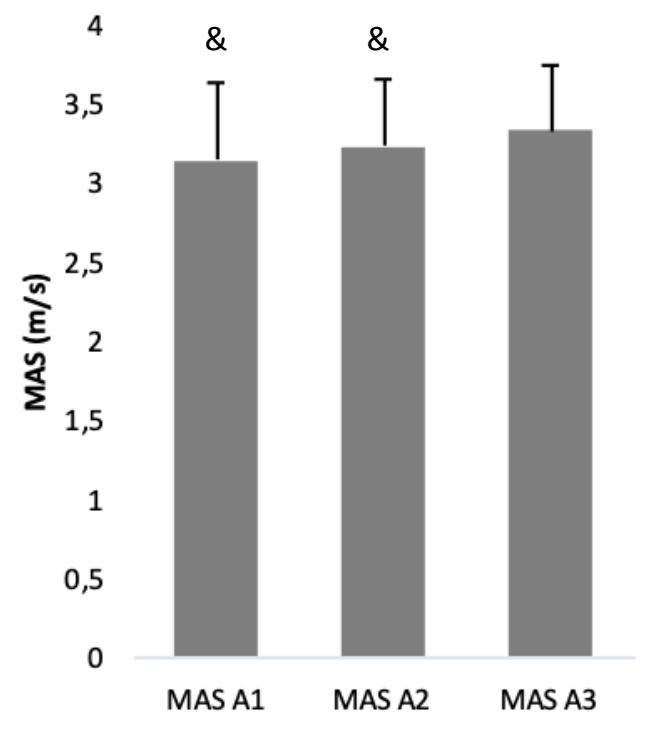

\&: significantly different from A3

Figure 2. Mean and standard deviation of (a) 5-min test and (b) maximal aerobic speed (MAS) after 1 month (A1), 3 months (A2) and 6 months (A3). 


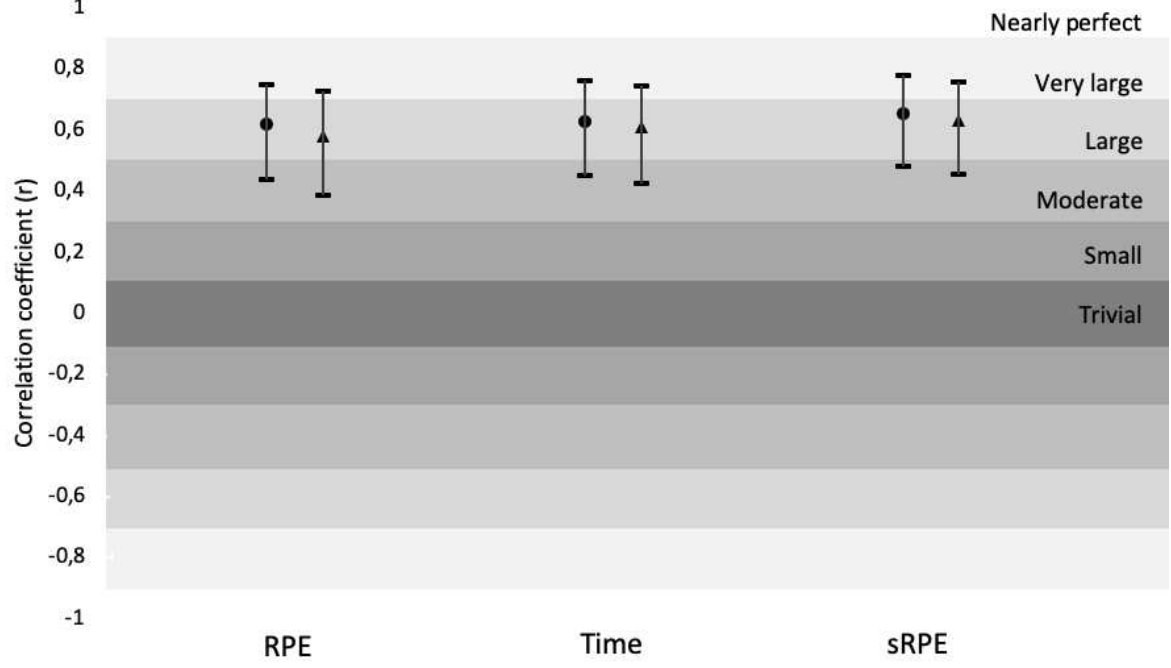

Figure 3. Correlation coefficients between maximal aerobic speed and the anthropometrics and accumulated training load parameters in the two observed periods (first period - between the first and the second assessment; second period - between the second and the third assessment). 
Click here to access/download RDM Data Profile XML DataProfile_4743290.xml 